\title{
High cognitive load may prevent the development of nociceptive hypersensitivity
}

\author{
Torta $\mathrm{DM}^{1,2 \#}$, De Laurentis $\mathrm{M}^{3^{*}}$, Eichin $\mathrm{KN}^{1 *}$, von Leupoldt $\mathrm{A}^{1}$, van den Broeke $\mathrm{EN}^{2}$, \\ Vlaeyen JWS ${ }^{1,4}$ \\ ${ }^{1}$ Health Psychology, KU Leuven, Leuven, Belgium \\ ${ }^{2}$ Institute of Neuroscience, UC Louvain, Brussels, Belgium \\ ${ }^{3}$ Department of Neuroscience, University of Turin, Turin, Italy \\ ${ }^{4}$ Experimental Health Psychology, Maastricht University, Netherlands \\ \#Corresponding author \\ Dr Diana M. Torta \\ Health Psychology, KU Leuven, Tiensestraat 102, 3000, Leuven, Belgium \\ * These authors contributed equally
}

Key words: Central sensitization, cognition, cognitive load, mechanical hypersensitivity, EEG 


\section{Abstract}

Whether, how, and which cognitive factors modulate the development of secondary hypersensitivity/hyperalgesia following central sensitization is not fully understood. Here we tested, in 60 healthy volunteers, whether being engaged in non-pain related cognitive demanding tasks: i) lessens the amount of hypersensitivity developed after an experimental procedure sensitizing nociceptive pathways; ii) modulates cortical responses to somatosensory stimuli (measured by electroencephalography, EEG). In the first experiment we validated a novel model in humans using low frequency stimulation (LFS) of the skin and demonstrated that it was able to successfully induce hypersensitivity to mechanical pinprick stimuli in the area surrounding the sensitized site. In the second and third experiments we engaged participants in tasks of increasing difficulty (the Eriksen Flanker Task in experiment 2, and a modified N-back task in experiment 3). We observed that hypersensitivity to mechanical stimuli still developed in experiment 2, i.e. the pinprick stimuli applied on the sensitized arm were perceived as more intense after LFS. In contrast, no such effect was observed in experiment 3, indicating that, at the group level, being engaged in high-cognitive load task may interfere with the development of mechanical hypersensitivity. Contrary to previous studies, which have used different methods to induce sensitization, we did not observe any increase in the cortical response to somatosensory stimuli applied on the sensitized arm. We conclude that i) the development of hyperalgesia partly depends on attention, and ii) the enhancement of cortical responses to somatosensory stimuli is related to the method used to induce central sensitization.

\section{Introduction}

The optimal balance between shielding goals and attending to dangerous signals is crucial for survival. Nociceptive stimuli are salient, signal potential danger and capture attention [5]. Nevertheless, this attentional capture is reduced when participants are engaged in tasks requiring mental operations that are sufficiently engaging, difficult and unrelated to pain 
$[12,13,19,29]$. Previous research has shown that cognitive load reduces pain reports and brain responses to brief transient nociceptive stimuli, and that it slows down reaction times to these stimuli $[13,16]$. Indeed, performing a task recruits cognitive resources that are no longer allocated to the concomitant incoming nociceptive stimulus, shielding the task performance from the disruptive effects of nociceptive input $[13,19]$. This possibility allows us to keep on pursuing our goals even in the face of pain [29].

Animal studies have shown that repeated and/or intense peripheral nociceptive input triggers an increase in the excitability of spinal nociceptive neurons, a phenomenon referred to as central sensitization (CS) (e.g. the "increased responsiveness of nociceptive neurons in the central nervous system to their normal or subthreshold input [11]). In humans, a direct measure of such excitation is not possible, and secondary hyperalgesia/hypersensitivity to mechanical stimuli (e.g. the increased sensitivity developing, after tissue injury, in the surrounding uninjured skin) is taken as one of its manifestations. Whether, how, and which cognitive factors modulate the development of secondary hypersensitivity/hyperalgesia ${ }^{1}$ following CS is not fully understood. A few studies have addressed this key question by experimentally inducing CS in healthy volunteers. Their results suggest that positive expectations, induced via placebo manipulations, can reduce the dimension of the area of hyperalgesia [14], whereas negative expectations induced by verbal suggestion increase the amount of hypersensitivity/hyperalgesia [31]. Furthermore, it has been reported that brief sessions of cognitive behavioral therapy aimed at better handling the painfulness of the stimuli led to a smaller extent of the hyperalgesic site as compared to a non- pain-specific training [17].

It is currently unknown whether cognitive load can interfere with the development of CS. It can be hypothesized that shielding cognition from the sensitization procedure would lead to less

\footnotetext{
${ }^{1}$ We will use the term hypersensitivity when the increased perception refers to nociceptive stimuli which are not perceived as painful at baseline, and hyperalgesia as the increased perception to stimuli which are perceived as painful at the baseline. See [30] for a discussion on this point.
} 
attentional resources engaged in the perception of the intense/prolonged nociceptive stimuli, and possibly reduce hypersensitivity. This would constitute a first direct evidence that attention directed to the sensitizing stimuli is a major contributor to the genesis of secondary hyperalgesia. To test this hypothesis, we performed 3 electroencephalographic (EEG) and behavioral experiments on 60 healthy volunteers. In the first experiment we validated a novel protocol to induce hypersensitivity in humans by using low frequency stimulation (LFS) [7]. The same protocol was then used in the following experiments in which cognitive tasks were administered during LFS. Both tasks were unrelated to pain, and engaging, but differed in the level of difficulty.

\section{Materials and Methods}

\section{Participants}

Participants were recruited at the KU Leuven and were naïve to the aims of research. Their participation was rewarded with either course credits or money (20 euros for a $2.30 \mathrm{~h}$ experiment). Informed written consent was obtained before the beginning of the study, which had been approved by the university ethical committee (G-2016 11 669). Sample size was calculated on the basis of previous studies and available literature [31]. By signing the exclusion criteria participants confirmed that they did not suffer from cardiovascular or respiratory diseases, chronic pain, acute pain at the time of testing, hearing problems; diagnosis of neurological and/or psychiatric syndromes. Participants were also excluded if they were pregnant, regular drug users, on stable medication (with the exception of contraceptive pill), significantly sleep deprived (slept less than 6 hours the night before the experiment), and if they had taken anti-inflammatory drugs $<12 \mathrm{~h}$ prior to the experiment. 
Sixty-four healthy participants were enrolled; four stopped during the sensitization procedure due to unbearable pain (two in experiment 1 and 2 in experiment 2). The final sample was composed of sixty participants: Twenty took part in experiment 1, (14 women, 6 men; median age 22 years, range 19-37), 19 in experiment 2 (15 women, 4 men; median age 22 years, range 18-40), 20 in experiment 3 (10 women, 11 men; median age 26, range 19-36). None of the participants took part in more than one experiment.

\section{Measures}

\section{Questionnaires}

Prior to the beginning of the experiment, participants filled in questionnaires including the Intolerance of Uncertainty Scale, Pain Catastrophizing Scale, the Positive and Negative Affect Schedule, and the Life Orientation Test - Revised. Questionnaires are part of larger prospective ongoing study. Therefore, the results will be presented here only in a descriptive way.

The Intolerance of Uncertainty Scale (IUS; [3]) includes 27 statements describing how people may feel in response to life uncertainties. Participants have to provide a 1 to 5 judgment on the scale 'Not at all characteristic of me' to 'Entirely characteristic of me'. In our scoring system higher scores point to the belief that uncertainty has negative and unfair implications.

The Pain Catastrophizing Scale (PCS;[23]) is a 13-item scale assessing catastrophic thinking in response to pain. The questionnaire consists of 3 subscales: helplessness, magnification, and rumination. Ratings are provided on a 5-point scale ranging from 0 (not at all) to 4 (always). High mean total scores indicate high pain catastrophizing.

The Positive and Negative Affect Schedule (PANAS; [39]) assesses the degree of positive and negative affect. It is composed of 20 affective words, 10 positive (e.g., interested, enthusiastic, proud, attentive) and 10 negative (e.g., irritable, frightened, ashamed, hostile). Participants rate how much they have felt as such over the past week. Each item is rated on a 5-point Likert scale 
ranging from 1 (very slightly or not at all) to 5 (extremely). High mean total scores indicate high positive or negative affect.

The Life Orientation Test-Revised (LOT-R; [18]) is a 10-item scale exploring expectancies for positive versus negative outcomes. Participants have to indicate their agreement ranging from 0 (strong disagreement) to 4 (strong agreement). Higher scores indicate greater optimism.

\section{Stimuli}

Low Frequency Stimulation (LFS). LFS was used to induce secondary mechanical hypersensitivity, a hallmark of CS [28] . It consisted of 2 minutes of electrical stimulation at $2 \mathrm{~Hz}$ (pulse width $2 \mathrm{~ms}$ ) [7]. The pulses were generated by a constant-current electrical stimulator (DS7, Digitimer Ltd, Welwyn Garden City, UK). The stimuli were applied by using a specifically designed electrode composed of 16 blunt stainless steel pins with a diameter of $0.2 \mathrm{~mm}$ protruding $1 \mathrm{~mm}$ from the base $[9,38]$. The pins were placed in a circle with a diameter of $10 \mathrm{~mm}$ and served as cathode. The stainless steel reference electrode, the anode, was placed surrounding the cathode and had an inner diameter of $22 \mathrm{~mm}$ and an outer diameter of $40 \mathrm{~mm}$. The intensity of stimulation was determined individually at 15 times the absolute detection threshold to a single pulse. The $15 \mathrm{x}$ threshold was established after running a pilot experiment assessing the compromise between feasibility and effectiveness of LFS using the 20x and 10x detection thresholds.

Mechanical hypersensitivity was tested by using pinprick stimuli which were applied using a calibrated stainless steel pinprick stimulator exerting a force of $128 \mathrm{mN}$ (MRC Systems, Heidelberg, Germany) and having a $0.25 \mathrm{~mm}$ probe diameter.

Electro-cutaneous innocuous stimuli consisted of $0.5 \mathrm{~ms}$ constant-current square waves electrical pulses (generated by a DS7 stimulator, Digitimer Ltd, Welwyn Garden City, UK). The stimuli were delivered via a bar stimulating electrode (Digitimer Ltd, Welwyn Garden City, 
UK) which consisted of two durable stainless steel disk electrodes of a $8 \mathrm{~mm}$ diameter with 30mm spacing. The electrode was held by means of a Velcro strap. Both mechanical and electro-cutaneous stimuli were applied on the volar forearm; $1.5 \mathrm{~cm}$ from the LFS stimulated region (and the homologue region of the control arm).

\section{EEG recording and analysis}

The EEG was recorded at a $1 \mathrm{kHz}$ sampling rate using a 129-channel amplifier and digitizer (Philips Electrical Geodesics Inc., Eugene, USA). Analysis of the EEG data was carried out using Letswave 6 (http://www.nocions.org/letswave). Extra-encephalic channels likely to be contaminated by artifacts were excluded from subsequent analyses [11]. These included the following leads (E44, E43, E38, E128, E127, E48, E49, E119, E126, E120, E114, E113, E121, E125). Continuous EEG recordings were re-referenced to the average of the remaining leads; a $50 \mathrm{~Hz}$ notch and a $0.5-30 \mathrm{~Hz}$ Butterworth zero phase filter were then applied. The data were segmented in $3 \mathrm{~s}$ epochs extending from -1 to $+2 \mathrm{~s}$ relative to stimulus onset. Artefacts were removed from the signal using an independent component analysis (ICA) [8]. Baseline correction was performed subtracting the signal from the -1 to $-0.1 \mathrm{~s}$ pre-stimulus interval; a further artifact correction eliminating epochs exceeding $100 \mu \mathrm{V}$ was carried out. The obtained waveforms were then averaged to obtain for each participant and time point (T0, T1, T2), two grand averages, one for the stimuli applied to the control arm and the other for the stimuli applied to the LFS arm. The latency and amplitude of the N1 and the P2 component of the Somatosensory Evoked Potentials (SEPs) were identified at pooled electrodes around the vertex Cz (E129); pooled electrodes were E7, E31, E55, E80, E106 and E129 (Cz). The N1 was identified as the most negative peak between 0.07 and 0.2 s post stimulus; the $\mathrm{P} 2$ as the most positive deflection following the N1 and occurring in an interval between 0.100 and $0.350 \mathrm{~s}$. Waves were subsequently visually inspected to confirm the automatic procedure. 


\section{General experimental procedure}

The three experiments shared the same experimental procedure. For the nature of the study, i.e. we first needed to validate the LFS procedure, the experiments were performed consecutively on three separate groups of participants. Upon arrival, participants signed the informed consent and the declaration regarding the exclusion criteria. Afterwards, participants completed questionnaires assessing the level of pain catastrophizing, intolerance of uncertainty, positive/negative affect and optimism.

The detection threshold for electro-cutaneous innocuous stimuli was then established using a staircase procedure. Low intensities were initially presented (starting from $0.1 \mathrm{mN}$ ) and increased by $0.1 \mathrm{mN}$ until the first stimulus was detected; afterwards the intensity was lowered until no longer perceived, and then increased again. The threshold was established after 3 reversals. The intensity used during the experiments was twice the detection threshold. At such intensity, the stimuli do not elicit any painful sensation, and brain responses to them are considered recruiting mainly $\mathrm{A} \beta$ fibers $[24,26]$. We chose for low-intensity electrical stimuli to compare the effects of Low Frequency Stimulation (see later) to those of High Frequency Stimulation (HFS) on brain responses to A $\beta$ inputs. Indeed, previous reports [34] have observed that, after HFS, brain responses to a variety of somatosensory inputs, even non nociceptive ones, are enhanced. Furthermore, we always ensured that the elicited sensation was non-painful, by asking for a rating on a scale ranging from 0 (no sensation) to 100 (the most intense pain imaginable). The rating of 50 constituted an anchor separating non-painful (0-50) to painful (50-100) sensations (e.g. [15,33,36-38]).

After establishing the threshold, the EEG net (Philips Electrical Geodesics Inc., Eugene, OR, USA) was mounted. Each participant performed three sessions, one before the sensitization procedure (i.e. LFS) (T0) and two after, at 20 (T1) and 45 (T2) minutes after the end of LFS. 
These time points were in line with previous findings obtained with HFS [36-38], and were confirmed by an initial pilot study, in which we tested for mechanical sensitivity from the end of LFS, each 5 minutes until 60 minutes. LFS was applied to one arm only, the dominant or non-dominant one; the arm was counterbalanced across participants. The other arm served as control. At each of the time points (T0, T1 and T2), participants received three mechanical pinprick stimuli on both the LFS and control arm, and they were requested to provide an average rating of its intensity on the previously described scale. Participants also received 30 lowintensity electrical stimuli on each arm to elicit somatosensory evoked potentials (SEPs). At the end of the 30 stimuli, a rating of intensity for these stimuli was also asked. The first kind of stimulus that was applied, either mechanical or electrical, and the first stimulated arm, either LFS or control, were counterbalanced across participants.

\section{Experiment 1}

In experiment 1, participants did not receive any specific instruction for what to do during LFS. Unbeknownst to them at the beginning of the stimulation, we asked for a rating of intensity of the LFS stimuli at the end of the two minute- stimulation. We also enquired volunteers on whether they used specific strategies during LFS to cope with the painfulness of the stimulation.

\section{Experiment 2}

Participants in experiment 2 performed an engaging task during LFS, the Eriksen Flanker Task. During this task participants were shown, on a Philips 32-inch monitor positioned at approximately $1 \mathrm{~m}$ from the participant, five arrowheads horizontally aligned and were instructed to indicate the direction towards which the central arrow points by either pressing the left or right mouse button. The mouse was held on the non- stimulated side. The four possible arrowhead combination $(\langle<\langle<,\langle\langle\rangle\langle\langle\rangle>\rangle$,$) , or \rangle\rangle\langle>\rangle)$ were presented pseudorandomly. In each trial, the arrowheads were presented for $200 \mathrm{~ms}$ and replaced by a blank 
screen until either a response was given or the maximal allowed time $(1,000 \mathrm{~ms})$ was elapsed. The inter-trial interval varied randomly between 600 and 1,000 ms (mean: $800 \mathrm{~ms}$ ) (see [22]). At the beginning of the experiment, participants performed 20 familiarization trials ( 5 for each of the four arrow combinations) during which they received a feedback about their performance. The feedback was not available during the actual experiment. The task started 90 seconds before LFS and continued for approximately 90 seconds after LFS. The instruction stressed the importance of both the speed and the accuracy of the response, and these two parameters were recorded and analyzed separately for the three time periods: Pre, During and Post LFS. After the end of the task we asked participants to judge how engaging and how difficult the task was on a scale from 0 (not difficult/engaging at all) to 10 (as difficult/engaging as possible). A rating of intensity of the LFS was also obtained. Given that a slightly different number of trials was presented to each participant (depending on the speed of the response), the accuracy was calculated in terms of percentage of correct responses.

\section{Experiment 3}

Participants in experiment 3 performed a modified version of an N-back task as used by [21]. They were shown, on the same screen used in experiment 2, a series of letters (A to E), each visible for $750 \mathrm{~ms}$, and followed by a $750 \mathrm{~ms}$ blank screen. The task was to detect matches between the actual letter and one presented two letters before (2-back task). Each string was composed of 15 letters, and the number of matches was pseudo-randomized. Participants were additionally requested to retain in memory the number of matches per string, and to report it at the end of the $22.5 \mathrm{~s}$ duration of the string. Before the experiment, participants performed a familiarization phase in which 5 strings were presented. During this phase they received feedback about their performance; the feedback was not provided during the actual experimental phase. Four strings were presented, during the experiment in the "Pre" LFS period, 5 during LFS and 4 in the "Post" LFS. 


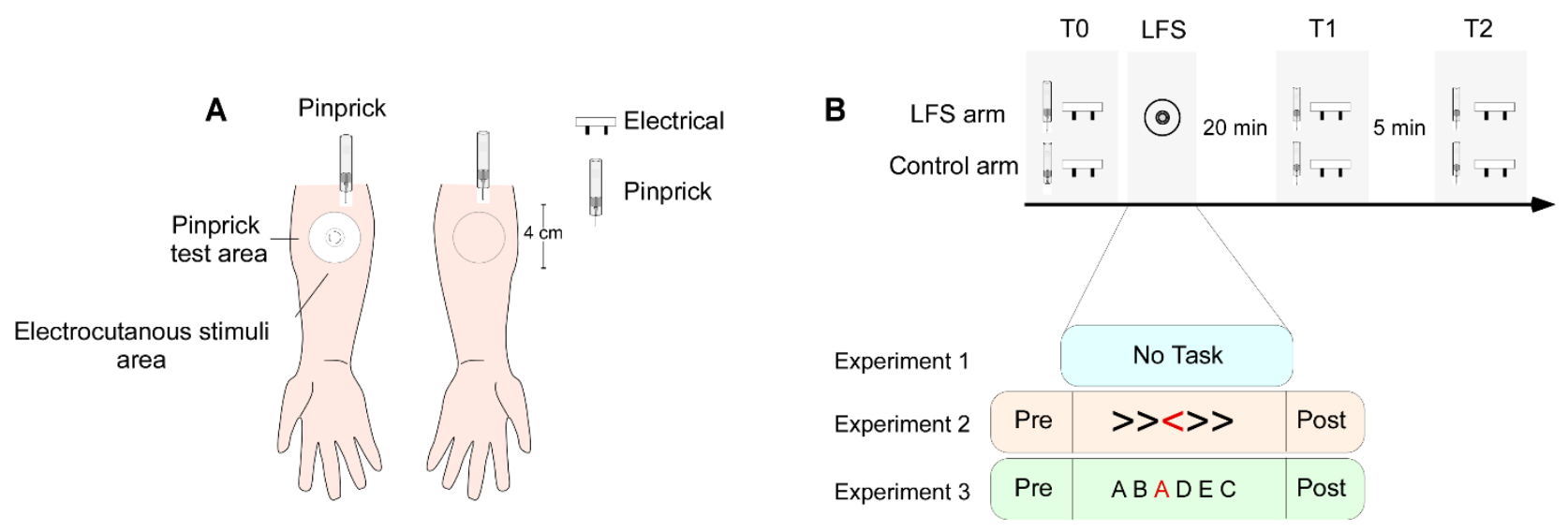

Figure 1: Experimental setup. Panel A. Participants received, on their volar forearm two kinds of stimuli, before and after an experimental procedure inducing sensitization (i.e. low frequency stimulation of the skin. Panel B. Three blocks were run for each participant, one before LFS, and two after, at 20 minutes (T1) and at 45 minutes (T2) from the end of LFS stimulation, i.e. 5 minutes after the end of T1. During LFS participants performed different tasks, depending on the experiment. In experiment 1 no task was performed, in experiment 2 volunteers performed an Eriksen Flanker Task, in experiment 3 they completed a modified $N$-Back task. These tasks started prior to the beginning of LFS and continued after its end.

\section{Statistical analysis}

Statistical analyses were conducted using IBM Statistics SPSS 19 (Armonk, NY: IBM Corp.). Assumption of normality was tested using the Wilk-Shapiro test, and the Greenhouse-Geisser correction was used where appropriate.

Changes in the perceived intensity of mechanical pinprick and electro-cutaneous stimuli, and in the magnitude of the SEPs (vertex N1 and P2) were assessed using three separate ANOVAs with the factors 'Time' (3 levels, T0, T1, T2) and 'Side' (LFS and control arm). The interaction 'Time' $x$ 'Side' was used to investigate the effects of LFS. In case of significant interactions, follow-up t-tests were conducted, and the level of significance of the alpha adjusted by the number of comparisons. 
The effect of the 'Phase' (pre, during and post LFS) was assessed on the accuracy of the response and reaction times in the Flanker task. The same effect of the 'Phase' was used as factor for the N-back task, outcomes variables were the accuracy of the response and the deliberation time for the number of matches. Correlations were run using two-tailed Person's $r$ on the pooled data of the three experiments.

\section{RESULTS}

Questionnaires. Descriptive statistics for the questionnaires are summarized in table 1.

\begin{tabular}{|c|c|c|c|c|c|}
\hline & $\begin{array}{c}\text { IUS total } \\
\text { score }\end{array}$ & $\begin{array}{c}\text { PANAS } \\
\text { (positive) }\end{array}$ & $\begin{array}{c}\text { PANAS } \\
\text { (negative) }\end{array}$ & $\begin{array}{c}\text { LOT-R } \\
\text { dispositional }\end{array}$ & PCS total \\
\hline $\begin{array}{l}\text { Experiment } \\
1\end{array}$ & $55.11 \pm 21.46$ & $\begin{array}{l}31.83 \pm \\
4.99\end{array}$ & $21.11 \pm 4.89$ & $16.83 \pm 4.21$ & $17.11 \pm 8.20$ \\
\hline $\begin{array}{l}\text { Experiment } \\
2\end{array}$ & $57.82 \pm 17.98$ & $\begin{array}{l}30.24 \pm \\
7.21\end{array}$ & $19.94 \pm 7.40$ & $13.71 \pm 3.56$ & $14.71 \pm 9.78$ \\
\hline $\begin{array}{l}\text { Experiment } \\
3\end{array}$ & $55.14 \pm 17.24$ & $\begin{array}{l}31.62 \pm \\
7.39\end{array}$ & $19.81 \pm 6.12$ & $15 \pm 4.29$ & $14.48 \pm 7.78$ \\
\hline
\end{tabular}

Table 1. Mean and standard deviations of the scores at psychological questionnaires.

Thresholds, intensity of stimulation and perceived intensity of LFS. The intensity of the LFS stimulation was $6.06( \pm 2.2) \mathrm{mN}, 7.41( \pm 2.06) \mathrm{mN}$, and $8.11( \pm 3.21) \mathrm{mN}$, for experiments 1,2 and 3, respectively. The intensity of the innocuous electro-cutaneous stimuli was $1.70( \pm 1.52)$ $\mathrm{mN}, 1.37( \pm 0.51) \mathrm{mN}$, and $1.46( \pm 0.53) \mathrm{mN}$, for experiments 1,2 and 3 , respectively. LFS was perceived on average as painful in all experiments (experiment 1: $65.30 \pm 13.43$, experiment 2: 68.11 \pm 19.14 , experiment 3: $66.48 \pm 16.08)$. 
Cognitive tasks. Due to a technical problem data from one participant from experiment 2 was not recorded. Therefore, the data refer to 18 participants for experiment 2 and 21 for experiment 3. On the 0 to 10 scale investigating how engaging the task was, the Eriksen Flanker task was rated on average $7.61 \pm 1.68$, and the $\mathrm{N}$-back $6.76 \pm 1.51$. The $\mathrm{N}$-back task was considered more difficult on the same 0 to 10 scale, being rated on average $6.76 \pm 1.37$ vs. a $4.28 \pm 2.24$ for the Eriksen Flanker Task.

The Flanker task accuracy was $91.07 \pm 12.24 \%, 92.74 \pm 11.11 \%$ and $93.97 \pm 12.37 \%$ in the pre, during and post LFS phases respectively, and the differences in accuracy in these three phases did not reach statistical significance $F(1,17)=1.667 ; p=0.204$; partial $\eta^{2}=0.089$. The reaction times for correct answers were of $529.91 \pm 42.99 \mathrm{~ms}$ before, $494.36 \pm 38.83 \mathrm{~ms}$ during and $511.62 \pm 43.06$ after LFS. These values were significantly different $F(1,17)=10.445$. $\mathrm{p}<0.001$. partial $\eta^{2}=0.381$. Participants became faster throughout the task, without losing their accuracy during LFS $\mathrm{t}(17)=4.108, \mathrm{p}=0.001$, Cohen's $\mathrm{d}=0.86$. Importantly, the reaction times increased significantly again post LFS $\mathrm{t}(17)=-2.490, \mathrm{p}=0.023$, Cohen's $\mathrm{d}=0.42$ indicating that the effects were not simply due to training.

Reaction times for errors were $439.72 \pm 62.19 \mathrm{~ms}, 415 \pm 55.36 \mathrm{~ms}$ and $366.63 \pm 179.29 \mathrm{~ms}$ in the pre, during and post LFS periods. This difference was not significant $F_{\mathrm{g}-\mathrm{g}}(1,13)=0.294$ $\mathrm{p}=0.656$ partial $\eta^{2}=0.022$.

The N-back accuracy reached an average of $45.60 \pm 35.89 \%, 32.14 \pm 27.63 \%, 44.04 \pm 28.12 \%$ correct responses in the pre, during and post LFS phases, respectively, with no statistically significant differences amongst them; $F(1,20)=1.593 ; p=0.216$; partial $\eta^{2}=0.074$. Indeed six out of 21 participants significantly improved their performance during LFS. Deliberation times for correct answers were of $2771 \pm 753 \mathrm{~ms}, 2232 \pm 804$, and $2197 \pm 781 \mathrm{~ms}$; for incorrect trials $2775 \pm 1358,2364 \pm 820$, and $2372 \pm 895 \mathrm{~ms}$. There were no statistically significant differences for incorrect trials $\mathrm{F}(2,30)=0.691 \mathrm{p}=0.509$ partial $\eta^{2}=0.044$. Conversely, deliberation times for 
correct trials significantly differed $\left(\mathrm{F}(2,30)=3.690, \mathrm{p}=0.042\right.$, partial $\left.\eta^{2}=0.270\right)$. More specifically, deliberation times decreased from pre to post $\mathrm{t}(13)=3.109 \mathrm{p}=0.008$ Cohen's $\mathrm{d}=$ 0.54 .

Figure 2 summarizes all these findings.
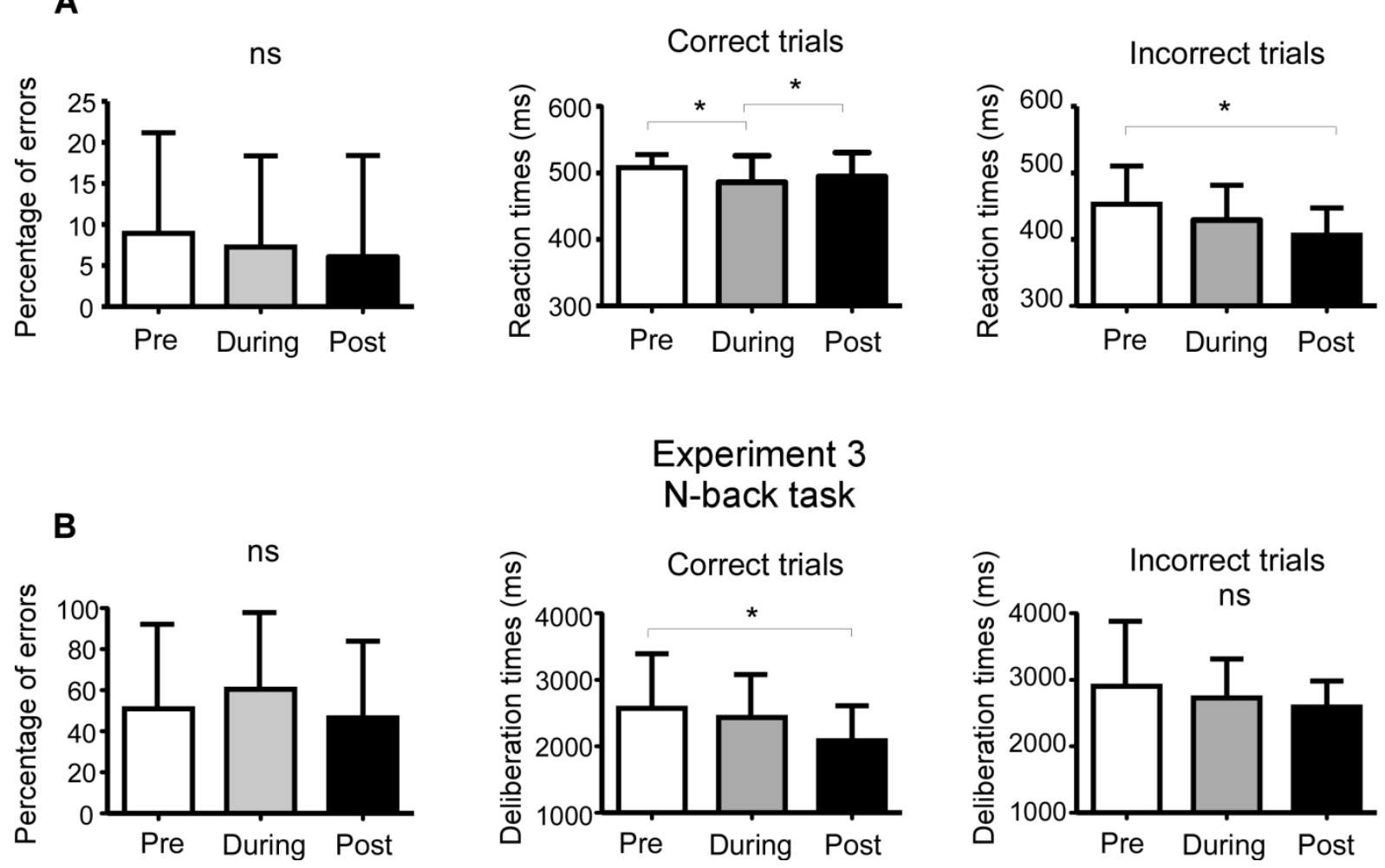

Figure 2. Performance at the tasks. Panel A. Participants were significantly faster during LFS as compared to before and after for correct trials. Reaction times to incorrect trials diminished across phases. Panel B. The performance at the N-back task was unchanged during LFS, whereas deliberation time decreased over time.

Mechanical hypersensitivity. Experiment 1. A Time' x 'Side' interaction $\mathrm{F}(2,38)=11.722$, $\mathrm{p}<0.001$ partial $\eta^{2}=0.382$ ) was observed on the perceived intensity of mechanical pinprick stimuli. Follow-up t-tests showed that stimuli applied on the LFS arm were rated as more 
intense at $\mathrm{T} 1(\mathrm{t}(19)=2.950 \mathrm{p}=0.008$, Cohen's $\mathrm{d}=0.52)$ as compared to T0. This increase was statistically borderline at $\mathrm{T} 2(\mathrm{t}(19)=2.068 \mathrm{p}=0.053$ Cohen's $\mathrm{d}=0.33)$, and did not survive the correction for multiple comparisons (Bonferroni corrected alpha 0.012). In contrast, the ratings for the stimuli applied on the control arm remained unchanged from T0 to $\mathrm{T} 1 \mathrm{t}(19)=-0.629$ $\mathrm{p}=0.537$ Cohen's $\mathrm{d}=0.08$ ). A mild habituation, not surviving Bonferroni correction, was observed at T2 $(\mathrm{t}(19)=-2.313 \mathrm{p}=0.032$ Cohen's $\mathrm{d}=0.28)$.

Experiment 2. The results of experiment 2 were similar to those obtained in experiment 1 . We observed a 'Time' x 'Side' interaction $\mathrm{F}(2,36)=11.168, \mathrm{p}<0.001$ partial $\left.\eta^{2}=0.383\right)$, explained by an increase in ratings for the stimuli applied at the LFS arm at $\mathrm{T} 1$ as compared to $\mathrm{T} 0(\mathrm{t}(18)=$ $3.129 \mathrm{p}=0.006$, Cohen's $\mathrm{d}=0.32$ ), but no difference for stimuli applied on the control arm $(\mathrm{t}(18)=1.010 \mathrm{p}=0.326$ Cohen's $\mathrm{d}=0.07)$. No difference between T2 and T0 was found (LFS arm $\mathrm{t}(18)=1.997 \mathrm{p}=0.061$ Cohen's $\mathrm{d}=0.22$; control arm $\mathrm{t}(18)-1.355 \mathrm{p}=0.192$ Cohen's $\mathrm{d}=0.14$. Overall, these findings suggest that the cognitive manipulation was ineffective in preventing the development of hypersensitivity at $\mathrm{T} 1$.

Experiment 3. In contrast, in experiment 3, no 'Time' $x$ 'Side' interaction was observed $\left(\mathrm{F}(2,38)=2.358 \mathrm{p}=0.108\right.$ partial $\left.\eta^{2}=0.110\right)$, indicating that a high cognitive load can prevent, at the group level, the development of hypersensitivity. Figure 3 and 4 summarize the results. The complete statistics are reported in the supplementary materials. 


\section{Experiment 1}

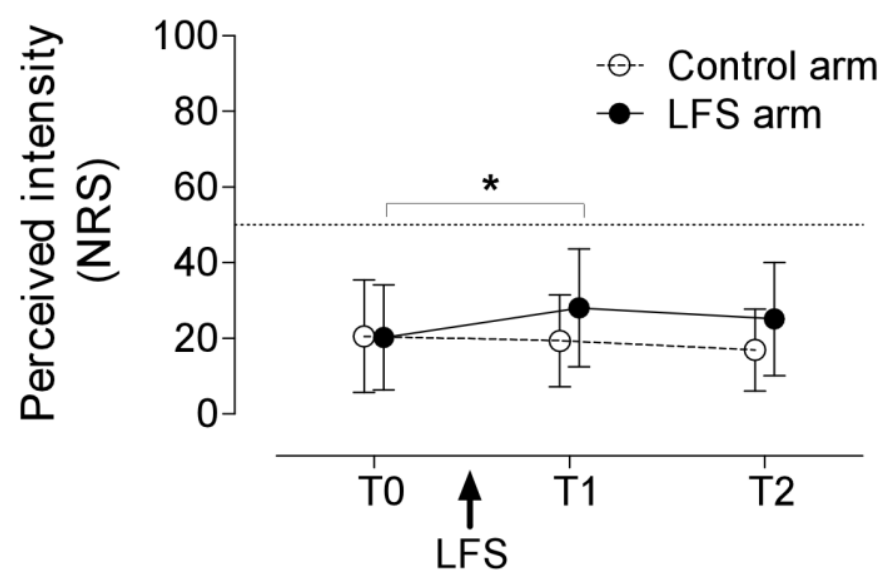

Experiment 2

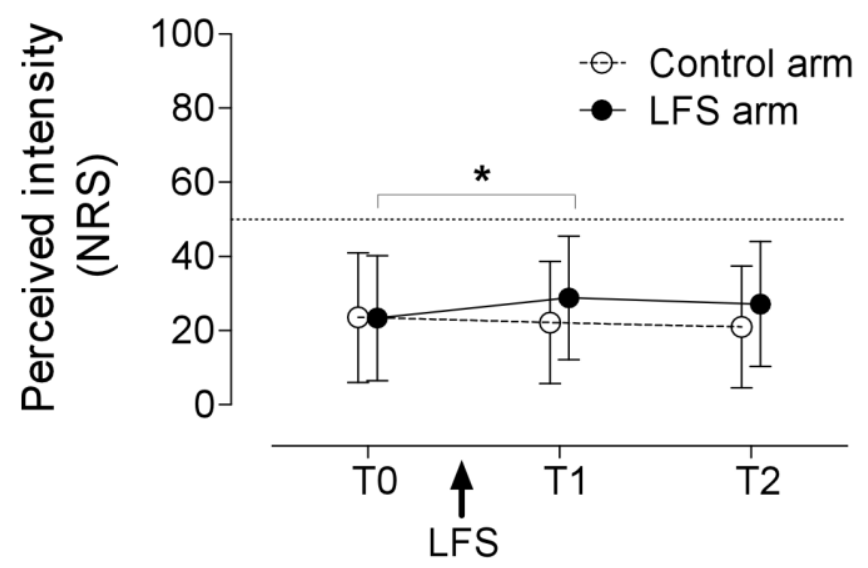

Experiment 3

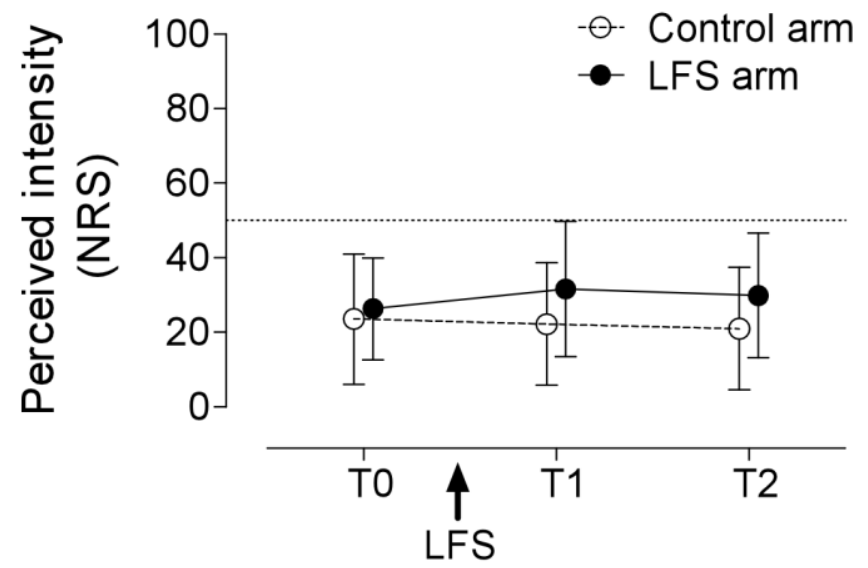


Figure 3. We found a significant Time $x$ Side interaction in the first two experiments driven by a significant increase in the ratings to stimuli applied on the LFS but not on the control arm. In contrast, such interaction was not present for experiment 3. Error bars represent standard deviations. NRS=Numerical Rating Scale; LFS=Low Frequency Stimulation. The dotted line at 50 represents the transition from a non-painful to a painful domain of sensation. 

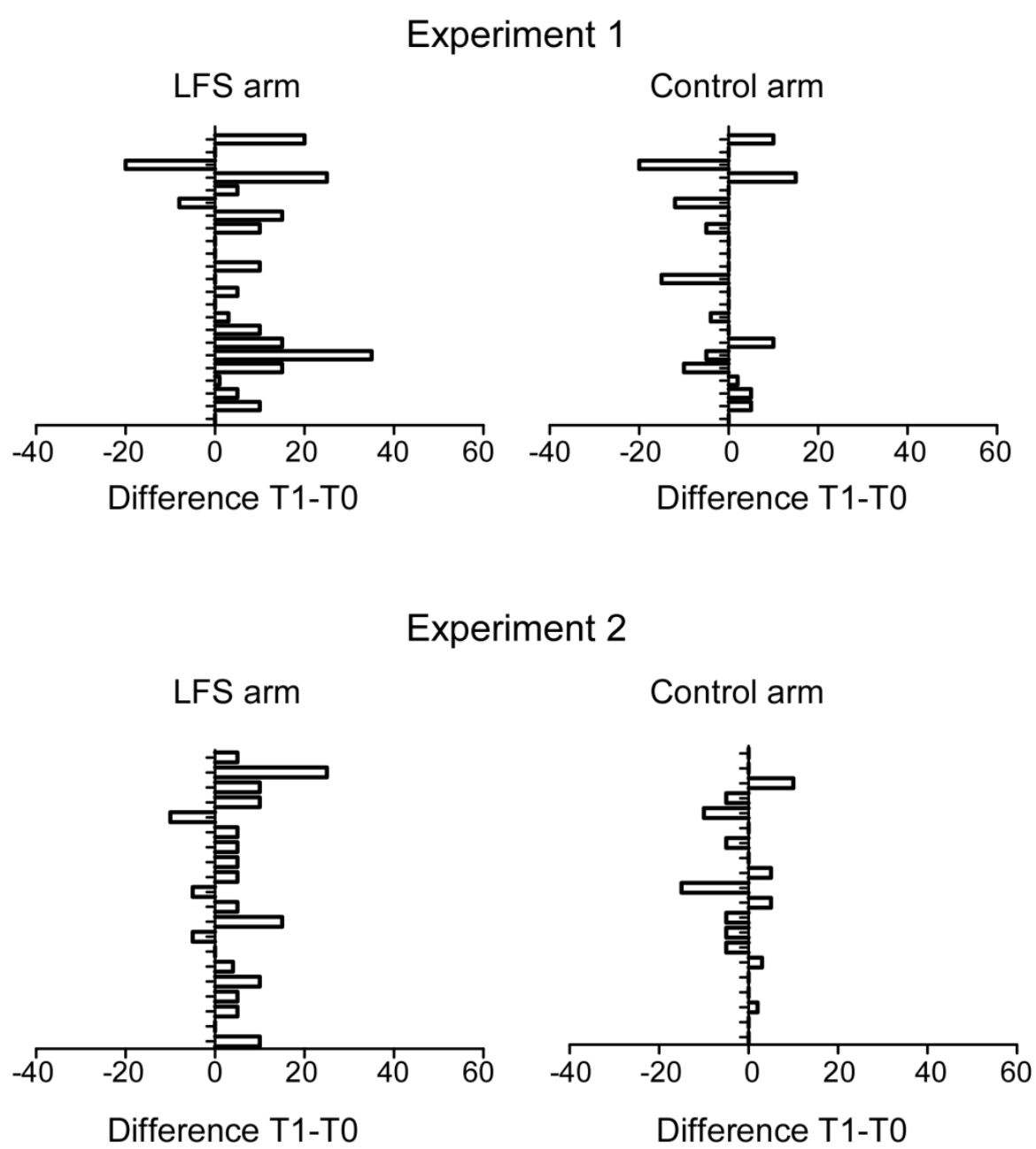

Experiment 3

LFS arm

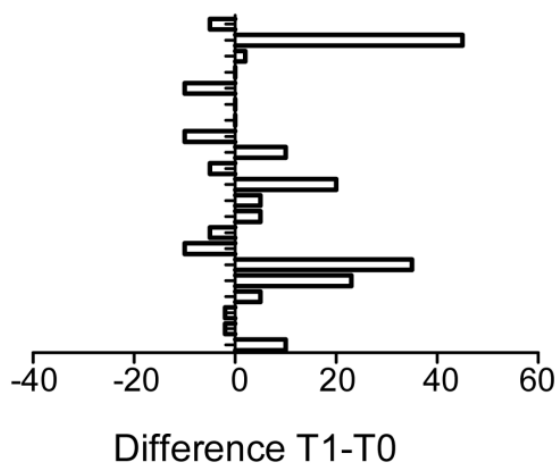

Control arm

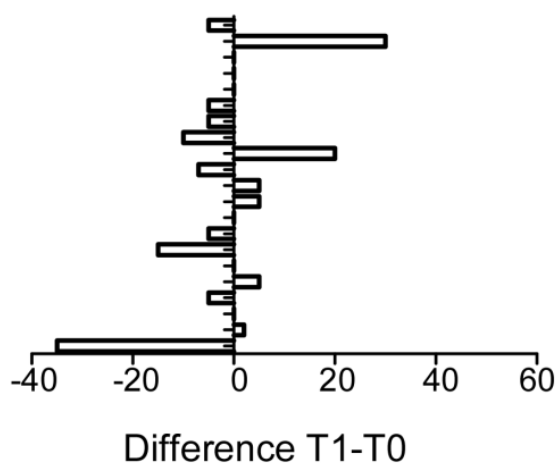

Figure 4. Details of the results at the individual level. Bars represent the scores provided for the pinprick stimulation. Negative values indicate lower scores at T1 as compared to TO. 
Tactile sensitivity. In none of the experiments, a Time $x$ Side interaction was observed (experiment $1 \mathrm{~F}(2,38)=-1.925 \mathrm{p}=0.160$ partial $\eta^{2}=0.092$; experiment $2 \mathrm{~F}(2,34)=-0.080 \mathrm{p}=0.923$ partial $\eta^{2}=0.005$; experiment $3 \mathrm{~F}(2,40)=-0.611 \mathrm{p}=0.548$ partial $\left.\eta^{2}=0.030\right)$, indicating that LFS had no effect on the reported intensity of innocuous stimuli (figure 5). 


\section{Experiment 1}

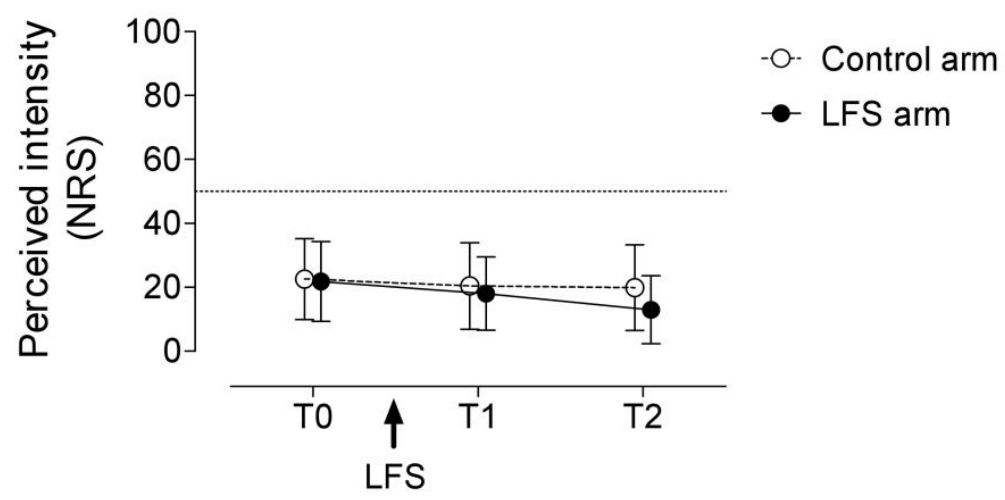

Experiment 2

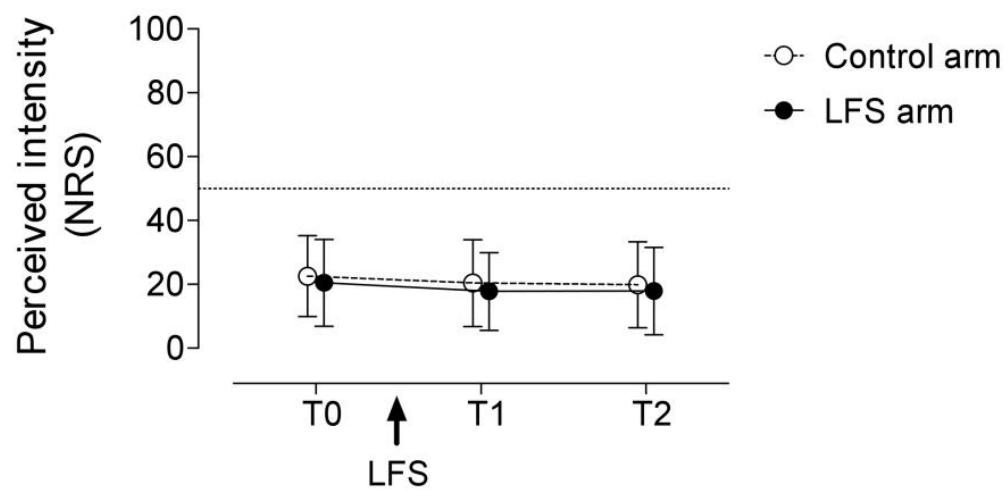

Experiment 3

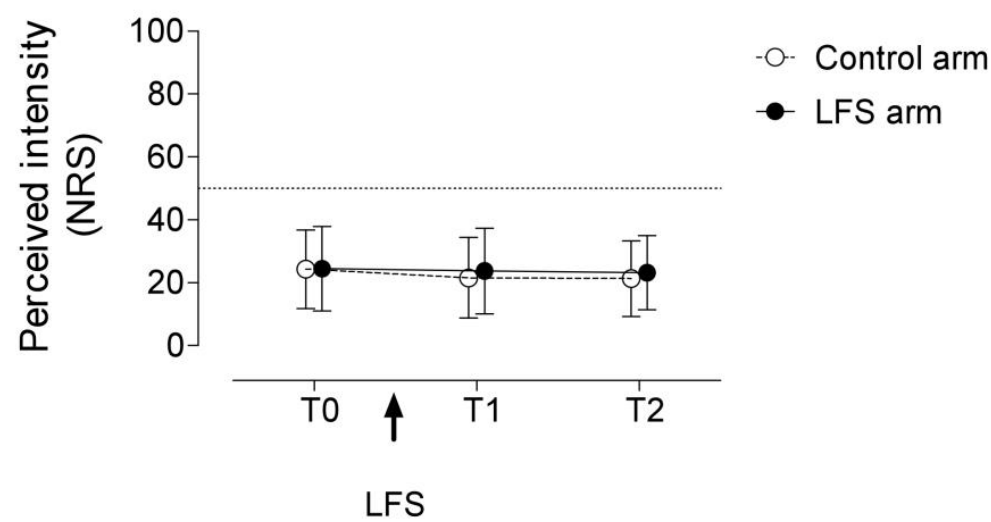

Figure 5. LFS did not influence the ratings to innocuous electrical stimuli, as evidenced by the lack of interaction between Time and Side in all three experiments. Error bars represent 
standard deviations. NRS=Numerical Rating Scale; LFS=Low Frequency Stimulation. The dotted line at 50 represents the transition from a non-painful to a painful domain of sensation.

Somatosensory Evoked Potentials (SEPS). N1 latency and amplitude. In none of the three experiments, a statistically significant Time $x$ Side interaction was observed on the latency and amplitude of the N1 component.

P2 latency and amplitude. Likewise, no statistically significant Time $x$ Side interaction was observed across experiments. Table $\mathrm{S} 1$ in the supplementary materials details the statistics, and Figure 6 illustrate the results 


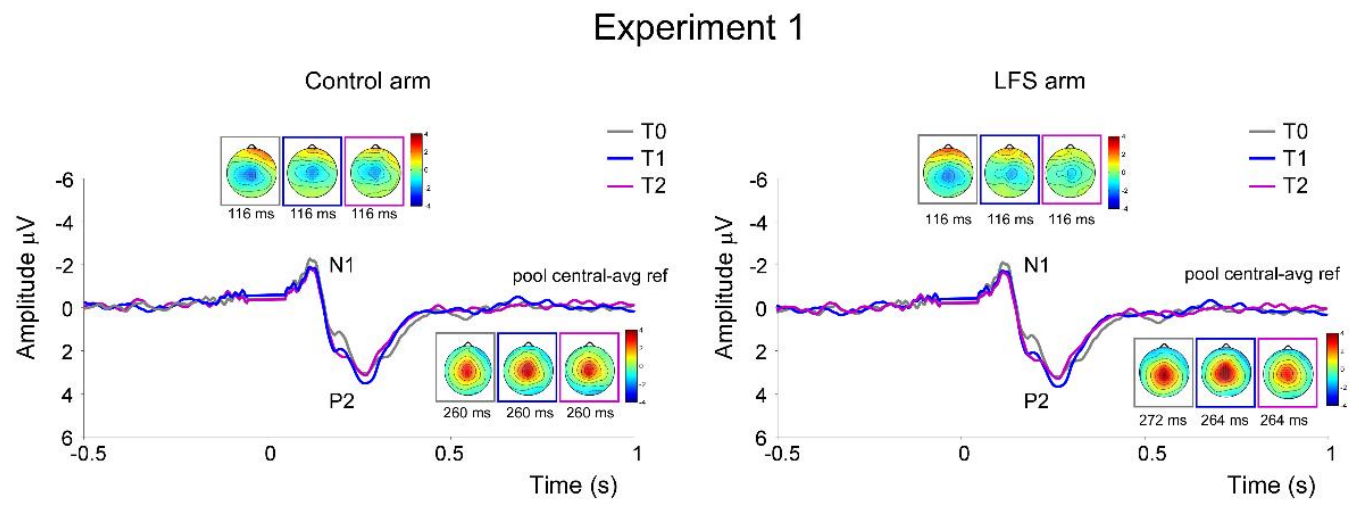

Experiment 2
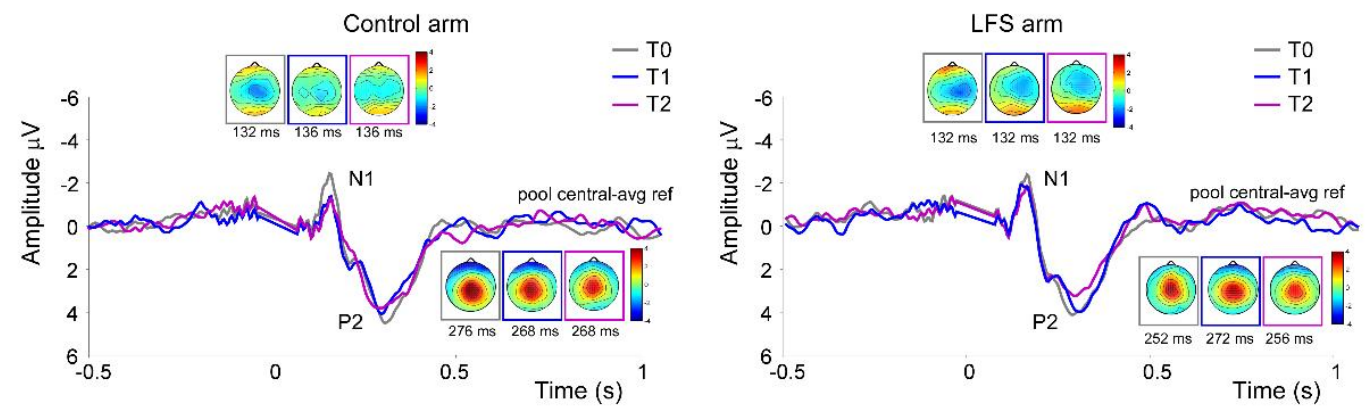

Experiment 3
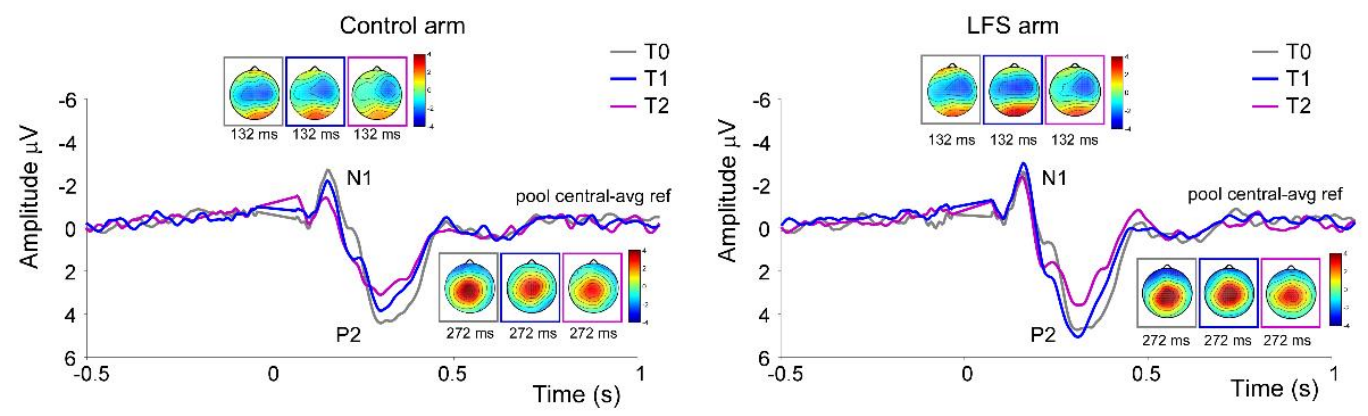

Figure 6. In contrast with previous studies using a different frequency to induce CS, we did not observe an increase of the N1 and P2 components of the SEPs. The electrical artifact around 0 s has been suppressed in the figure for visualization purposes.

Correlations. After pooling all data from the three experiments together to increase the numerosity of the cases, we observed a statistically significant correlation between the intensity 
of the LFS stimulation and the amplitude of the N1 at the LFS arm at T1 $(r=-0.303 p=0.030$, $\mathrm{R}^{2}=0.092$ ). The correlation at $\mathrm{T} 2$ was of $\mathrm{r}=-0.274 \mathrm{p}=0.051, \mathrm{R}^{2}=0.075$. No such correlation was found for the P2 (T1; $r=0.129 \mathrm{p}=0.364, \mathrm{R}^{2}=0.016$; $\mathrm{T} 2$ : $\mathrm{r}=0.149 \mathrm{p}=0.295, \mathrm{R}^{2}=0.022$ ). The amplitude of the N1 at the LFS arm at T1 and the pinprick perception were also uncorrelated $\left(\mathrm{r}=-0.161 \mathrm{p}=0.258, \mathrm{R}^{2}=0.026\right.$ ). Finally, whereas we found no relationship between the intensity of LFS stimulation and the amount of developed hypersensitivity $\left(r=0.180 \mathrm{p}=0.204, \mathrm{R}^{2}=0.032\right)$, we did observe a correlation between the perceived intensity of LFS and the amount of hypersensitivity, both at $\mathrm{T} 1\left(\mathrm{r}=0.394 \mathrm{p}=0.002 \mathrm{R}^{2}=0.155\right)$ and $\mathrm{T} 2\left(\mathrm{r}=0.415 \mathrm{p}=0.001 \mathrm{R}^{2}=0.172\right)$. Figure 7 and 8 summarize the results.

T1
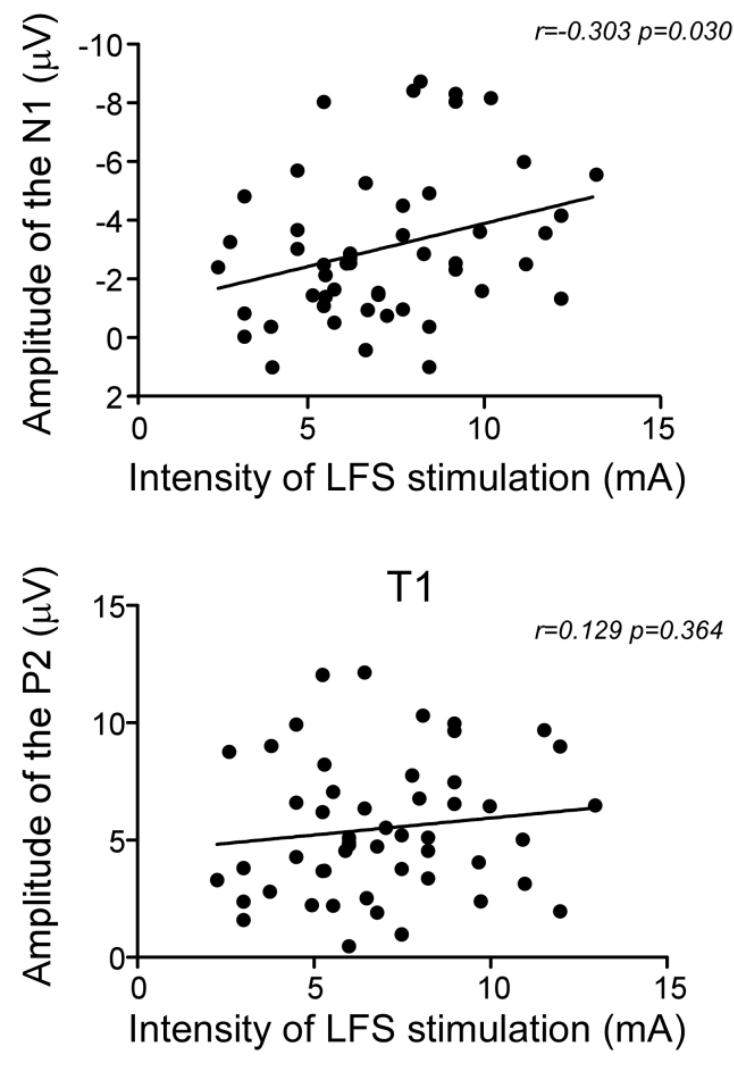

T2
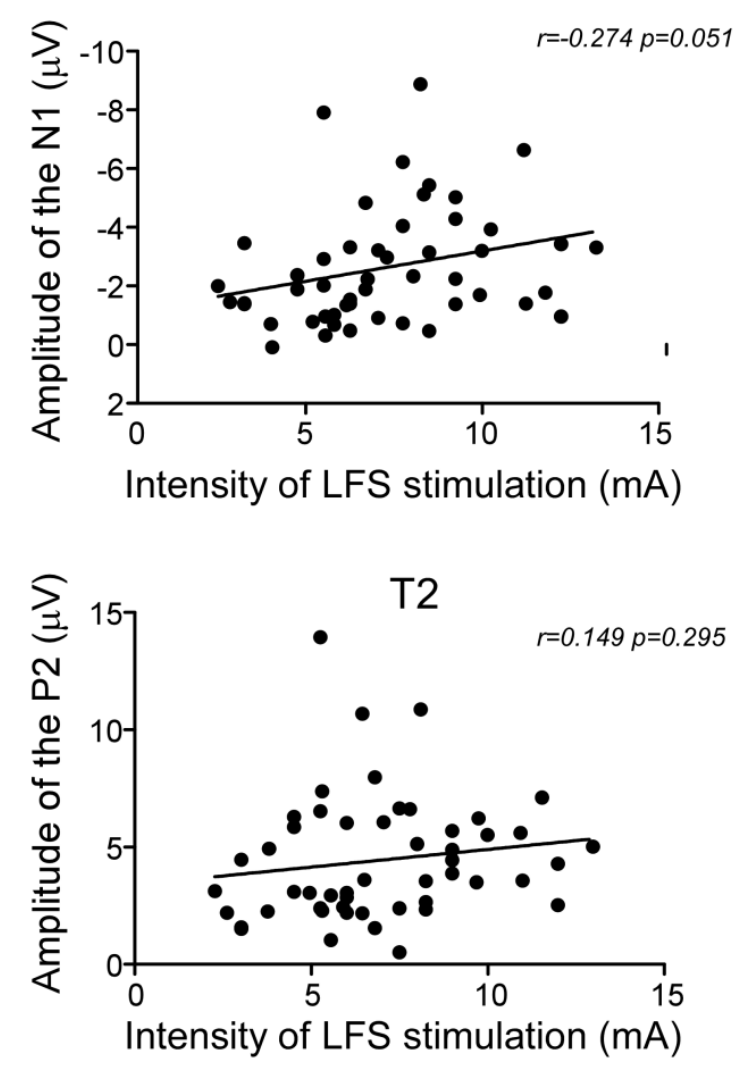

Figure 7. We observed significant correlations between the LFS intensity of stimulation and the amplitude of the signal (N1) at T1 and, marginally, at T2. No such correlation was observed 
for the amplitude of the P2. The correlations are calculated on the data of the three pooled experiments.

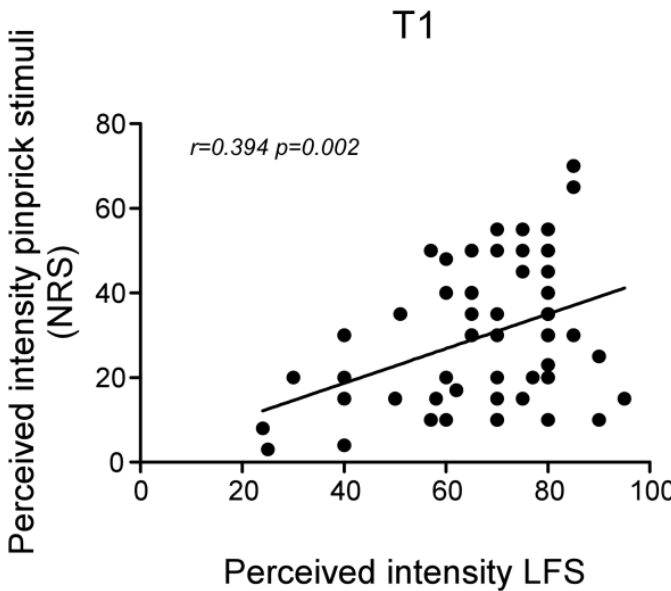

(NRS)

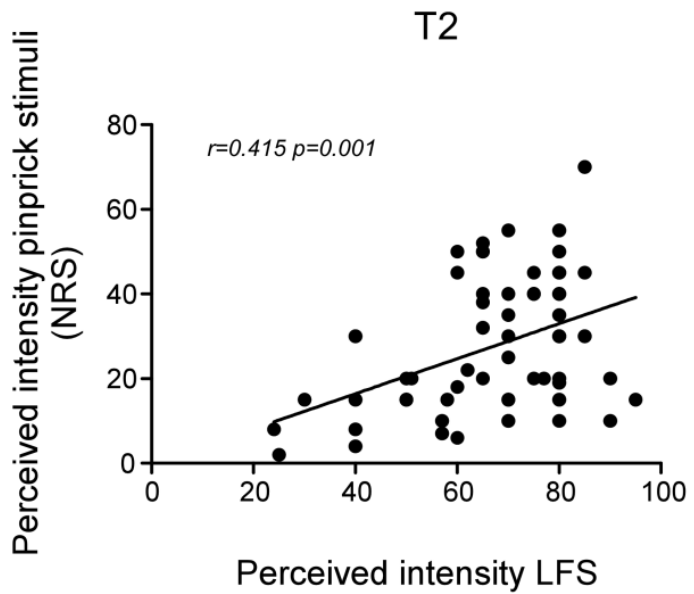

(NRS)

Figure 8. At both $T 1$ and T2, the amount of hypersensitivity was associated with the perceived intensity of LFS during sensitization, rather than with the actual LFS intensity that was used. The correlations are calculated on the data of the three pooled experiments.

\section{DISCUSSION}

Despite their clinical value, reports investigating whether, how, and which cognitive factors contribute to the development of hypersensitivity/hyperalgesia are still scarce $[14,17,31]$. Furthermore, the neural mechanisms of such effects, if they exist, largely remain to be elucidated [10]. In this study we have tested, for the first time, in three separate studies, whether being engaged in non-pain related cognitive tasks during sensitization results in reduced mechanical hypersensitivity 20 (T1) and 45 (T2) minutes after the end of the sensitization procedure (e.g. abolished the interaction Time x Side typically occurring after sensitization). To achieve our aim, we have first validated, in humans, a novel protocol to induce 
hypersensitivity using Low Frequency Stimulation (LFS) at $2 \mathrm{~Hz}$ for 2 minutes (experiment 1). Subsequently, in experiments 2 and 3, we have requested participants to engage in cognitive tasks of increasing difficulty while they underwent LFS. We have measured both the increase in perceived intensity of pinprick stimuli and brain responses to innocuous electro-cutaneous stimuli (Somatosensory Evoked Potentials, SEPs). Indeed, previous studies using High Frequency Stimulation of the skin, another procedure that has shown to induce robust hyperalgesia, have reported that, after sensitization, the middle latency (120-200 ms) negative component of the event related potentials (ERPs) measured at the vertex $(\mathrm{Cz})$ was increased for a broad range of somatosensory and non-somatosensory, i.e. visual stimuli $[27,30,33,34,36]$.

Our results show that mechanical hypersensitivity can still develop when a moderately engaging task is performed during LFS, but is attenuated when a difficult task, involving a higher cognitive load is used. This evidence shows that, under certain conditions, attention can contribute to the development of mechanical hypersensitivity, at least when LFS is used.

The present findings also indicate that LFS, contrary to HFS, does not induce an increase in the magnitude of the middle latency component of the ERPs. This, together with the lack of correlation between the N1 elicited by stimuli applied on the LFS arm at T1 and the perceived pinprick intensity for stimuli applied on the same arm also at $\mathrm{T} 1$, strongly supports that the increase in the middle latency component and the increase in perceived intensity of mechanical stimuli reflect two distinct processes.

\section{LFS induces mechanical hypersensitivity}

Electrical stimulation of the skin, as compared to capsaicin, has the advantage of inducing hypersensitivity without triggering an ongoing burning sensation that can per se capture attention. For its characteristics of brevity and intensity, HFS did not represent the best model to test top-down inhibitory effects as the whole procedure lasts 50 seconds, of which only 5 of 
intense painful stimuli. Therefore we validated, in humans, the protocol proposed by Ikeda and colleagues [7]. The authors demonstrated, in vitro, that both HFS and LFS of the skin induce increased post-synaptic potential (PSP) in nociceptive pathways, with LFS sensitizing the spino-periacqueductal gray pathway instead of the spino-parabrachial pathway. We observed in humans that such a protocol, at $2 \mathrm{~Hz}$ for 2 minutes is also capable of inducing a significant hypersensitivity to pinprick mechanical stimuli. This is also in line with other reports showing that, in humans, both low and high frequency stimulation of the skin may result in a facilitation of nociceptive processing [2,4]. For instance Biurrun-Manresa and colleagues showed that LFS induced a long-lasting facilitation of the Nociceptive Withdrawal reflex, which is considered a measure of spinal nociceptive processing. [2] (for contradicting findings see however [9]).

\section{LFS does not induce an increase of the vertex negative middle latency component}

SEPs were not enhanced after LFS. Accumulating evidence shows that such increase is unlikely a correlate of hypersensitivity and hyperalgesia [1]. Indeed, albeit to a lesser extent, an enhancement in the magnitude of cortical potentials in response to stimuli presented on the sensitized arm has been also observed for visual stimuli [27], and changes in brain responses are uncorrelated with the changes in pain reports [1]. Currently, it remains unclear which processes lead to an increase in the magnitude of the brain response after HFS and capsaicin $[25,32,33,35]$. A previous study [25] investigated whether sensitization procedures (HFS in that case) would increase attentional allocation towards the sensitized arm, thereby resulting in a prioritization of stimuli presented on the sensitized arm over those presented on the control arm. Surprisingly, the findings did not uphold the hypothesis, questioning whether the increase in the middle latency component represents an indirect reflection of perceptual biases towards the sensitized arm.

Secondary mechanical hypersensitivity is reduced by cognitive load 
The main finding of the present paper is that the amount of mechanical hypersensitivity that develops after LFS is modulated by the concomitant execution of a difficult cognitive task. In more detail, our data indicate that cognitive shielding against intense/prolonged stimuli inducing hypersensitivity is effective in some individuals, and provided that the cognitive load is sufficiently high. Previous studies have suggested that some individuals are better at remaining engaged in a task (attention types, A-types) while painful stimuli are presented, whereas other are more easily distracted by the pain (pain type, P-types) [6,20]. An interesting possibility is that similar features play a role in the development of hypersensitivity as well. Of note, the present cognitive task was not individually tailored for difficulty; future studies may investigate whether cognition has a limited modulatory effect i.e. only "A-type" individuals may benefit from cognitive shielding or whether the proper balance between the perceived pain intensity and the difficulty of the task may contribute to exert analgesic effects in every participant. Two caveats should also be put forward. First, due to the necessity to first validate the LFS procedure, the 3 experiments were conducted one after the other, leading to our methodological choice of analyzing them separately. Second, our analysis of interest was the identification of a Time $x$ Side interaction in the perception of mechanical stimuli and this interaction did not reach the statistical significance in the third experiment. Nevertheless (see supplementary material) a main effect of Time was observed, driven by significant differences between the two arms at $\mathrm{T} 1$ and $\mathrm{T} 2$. This result indicates that hyperalgesia did develop in some individuals.

\section{Modulating hypersensitivity: different strategies, different mechanisms?}

Two previous studies using repeated administration of heat painful stimuli to induce hypersentivity/hyperagelsia showed that placebo manipulations [14] as well as short sessions of repeated cognitive behavioral therapy over 8 days [17] were effective in reducing the amount of hyperalgesia. These results indicate that expectations play a major role in the development 
of hyperalgesia, as shown by a report by van den Broeke and colleagues [31]. In this latter paper the authors demonstrated that a mere verbal suggestion was able, in a 'nocebo' group vs. a control group, to increase the perceived intensity of mechanical stimuli after HFS. Whether expectations and cognitive load interfere with the development of hypersensitivity via the same or different mechanisms remains currently an open question. However, one important methodological difference is that both studies [14 and 17] included several sessions across days. In contrast, our study is the first one reporting that hypersensitivity can be reduced even in a single session, suggesting that at least of part of the development of hypersensitivity/hyperalgesia is under the control of attentional mechanisms.

To conclude, LFS can be used as an alternative method to induce hypersensitivity to mechanical stimuli, and cognitive load can modulate such effects in certain individuals and under certain conditions.

\section{References}

[1] Biurrun Manresa J, Kaeseler Andersen O, Mouraux A, van den Broeke EN. High frequency electrical stimulation induces a long-lasting enhancement of event-related potentials but does not change the perception elicited by intra-epidermal electrical stimuli delivered to the area of increased mechanical pinprick sensitivity. PloS one 2018;13(9):e0203365.

[2] Biurrun Manresa JA, Morch CD, Andersen OK. Long-term facilitation of nociceptive withdrawal reflexes following low-frequency conditioning electrical stimulation: a new model for central sensitization in humans. European journal of pain 2010;14(8):822-831.

[3] Buhr K, Dugas MJ. The Intolerance of Uncertainty Scale: psychometric properties of the English version. Behaviour research and therapy 2002;40(8):931-945.

[4] De Col R, Maihofner C. Centrally mediated sensory decline induced by differential C-fiber stimulation. Pain 2008;138(3):556-564.

[5] Eccleston C, Crombez G. Pain demands attention: a cognitive-affective model of the interruptive function of pain. Psychological bulletin 1999;125(3):356-366.

[6] Erpelding N, Davis KD. Neural underpinnings of behavioural strategies that prioritize either cognitive task performance or pain. Pain 2013;154(10):2060-2071.

[7] Ikeda H, Stark J, Fischer H, Wagner M, Drdla R, Jager T, Sandkuhler J. Synaptic amplifier of inflammatory pain in the spinal dorsal horn. Science 2006;312(5780):1659-1662. 
[8] Jung TP, Makeig S, Humphries C, Lee TW, McKeown MJ, Iragui V, Sejnowski TJ. Removing electroencephalographic artifacts by blind source separation. Psychophysiology 2000;37(2):163-178.

[9] Klein T, Magerl W, Hopf HC, Sandkuhler J, Treede RD. Perceptual correlates of nociceptive longterm potentiation and long-term depression in humans. The Journal of neuroscience : the official journal of the Society for Neuroscience 2004;24(4):964-971.

[10] Kucyi A, Salomons TV, Davis KD. Cognitive behavioral training reverses the effect of pain exposure on brain network activity. Pain 2016;157(9):1895-1904.

[11] Kuttikat A, Noreika V, Chennu S, Shenker N, Bekinschtein T, Brown CA. Altered Neurocognitive Processing of Tactile Stimuli in Patients with Complex Regional Pain Syndrome. The journal of pain : official journal of the American Pain Society 2018;19(4):395-409.

[12] Legrain V, Crombez G, Mouraux A. Controlling attention to nociceptive stimuli with working memory. PloS one 2011;6(6):e20926.

[13] Legrain V, Crombez G, Plaghki L, Mouraux A. Shielding cognition from nociception with working memory. Cortex; a journal devoted to the study of the nervous system and behavior 2013;49(7):1922-1934.

[14] Matre D, Casey KL, Knardahl S. Placebo-induced changes in spinal cord pain processing. The Journal of neuroscience : the official journal of the Society for Neuroscience 2006;26(2):559563.

[15] Mouraux A, Plaghki L. Are laser-evoked brain potentials modulated by attending to first or second pain? Pain 2007;129(3):321-331.

[16] Romero YR, Straube T, Nitsch A, Miltner WH, Weiss T. Interaction between stimulus intensity and perceptual load in the attentional control of pain. Pain 2013;154(1):135-140.

[17] Salomons TV, Moayedi M, Erpelding N, Davis KD. A brief cognitive-behavioural intervention for pain reduces secondary hyperalgesia. Pain 2014;155(8):1446-1452.

[18] Scheier MF, Carver CS, Bridges MW. Distinguishing optimism from neuroticism (and trait anxiety, self-mastery, and self-esteem): a reevaluation of the Life Orientation Test. Journal of personality and social psychology 1994;67(6):1063-1078.

[19] Schrooten MG, Van Damme S, Crombez G, Peters ML, Vogt J, Vlaeyen JW. Nonpain goal pursuit inhibits attentional bias to pain. Pain 2012;153(6):1180-1186.

[20] Seminowicz DA, Mikulis DJ, Davis KD. Cognitive modulation of pain-related brain responses depends on behavioral strategy. Pain 2004;112(1-2):48-58.

[21] Sprenger C, Eippert F, Finsterbusch J, Bingel U, Rose M, Buchel C. Attention modulates spinal cord responses to pain. Current biology : CB 2012;22(11):1019-1022.

[22] Sucec J, Herzog M, Van Diest I, Van den Bergh O, von Leupoldt A. The impact of dyspnea and threat of dyspnea on error processing. Psychophysiology 2019;56(1):e13278.

[23] Sullivan M, Bishop S, Pivik J. The pain catastrophizing scale: development and validation. Psychological assessment 1995;7:524-532.

[24] Torta DM, Churyukanov MV, Plaghki L, Mouraux A. The effect of heterotopic noxious conditioning stimulation on Adelta-, C- and Abeta-fibre brain responses in humans. The European journal of neuroscience 2015;42(9):2707-2715.

[25] Torta DM, Filbrich L, Van Den Broeke EN, Legrain V. No perceptual prioritization of non-nociceptive vibrotactile and visual stimuli presented on a sensitized body part. Scientific reports 2018;8(1):5359.

[26] Torta DM, Legrain V, Mouraux A. Looking at the hand modulates the brain responses to nociceptive and non-nociceptive somatosensory stimuli but does not necessarily modulate their perception. Psychophysiology 2015;52(8):1010-1018.

[27] Torta DM, Van Den Broeke EN, Filbrich L, Jacob B, Lambert J, Mouraux A. Intense pain influences the cortical processing of visual stimuli projected onto the sensitized skin. Pain 2017;158(4):691-697.

[28] Treede RD. Gain control mechanisms in the nociceptive system. Pain 2016;157(6):1199-1204. 
[29] Van Damme S, Legrain V, Vogt J, Crombez G. Keeping pain in mind: a motivational account of attention to pain. Neuroscience Biobehavioral Reviews 2009;34(2):204-213.

[30] van den Broeke EN, de Vries B, Lambert J, Torta DM, Mouraux A. Phase-locked and non-phaselocked EEG responses to pinprick stimulation before and after experimentally-induced secondary hyperalgesia. Clinical neurophysiology : official journal of the International Federation of Clinical Neurophysiology 2017;128(8):1445-1456.

[31] van den Broeke EN, Geene N, van Rijn CM, Wilder-Smith OH, Oosterman J. Negative expectations facilitate mechanical hyperalgesia after high-frequency electrical stimulation of human skin. European journal of pain 2014;18(1):86-91.

[32] van den Broeke EN, Hartgerink MD, Butler J, Lambert J, Mouraux A. Central sensitization increases the pupil dilation elicited by mechanical pinprick stimulation. Journal of neurophysiology 2019.

[33] van den Broeke EN, Lambert J, Huang G, Mouraux A. Central Sensitization of Mechanical Nociceptive Pathways Is Associated with a Long-Lasting Increase of Pinprick-Evoked Brain Potentials. Frontiers in human neuroscience 2016;10:531.

[34] Van Den Broeke EN, Mouraux A. High frequency electrical stimulation of human skin induces heterotopical mechanical and heat hyperalgesia and enhanced responses to vibrotactile input. Journal of neurophysiology 2014.

[35] van den Broeke EN, Mouraux A, Groneberg AH, Pfau DB, Treede RD, Klein T. Characterizing pinprick-evoked brain potentials before and after experimentally induced secondary hyperalgesia. Journal of neurophysiology 2015;114(5):2672-2681.

[36] van den Broeke EN, van Heck CH, Ceelen LA, van Rijn CM, van Goor H, Wilder-Smith OH. The effect of high-frequency conditioning stimulation of human skin on reported pain intensity and event-related potentials. Journal of neurophysiology 2012;108(8):2276-2281.

[37] van den Broeke EN, van Heck CH, van Rijn CM, Wilder-Smith OH. Neural correlates of heterotopic facilitation induced after high frequency electrical stimulation of nociceptive pathways. Molecular pain 2011;7:28.

[38] van den Broeke EN, van Rijn CM, Biurrun Manresa JA, Andersen OK, Arendt-Nielsen L, WilderSmith $\mathrm{OH}$. Neurophysiological correlates of nociceptive heterosynaptic long-term potentiation in humans. Journal of neurophysiology 2010;103(4):2107-2113.

[39] Watson D, Clark LA, Tellegen A. Development and validation of brief measures of positive and negative affect: the PANAS scales. Journal of personality and social psychology 1988;54(6):1063-1070. 